\title{
Determinants of Exclusive Breastfeeding Intention in Pregnant Women in Birjand in 2020: Application of Integrated Behavioral Model
}

\author{
Zari Gandomi (iD ${ }^{1}$, Gholamreza Sharifzadeh (iD ${ }^{2}$ and Ensiyeh Norozi (iD) ${ }^{3, *}$ \\ ${ }^{1}$ Student Research Committee, Social Determinants of Health Research Center, Birjand University of Medical Sciences, Birjand, Iran \\ ${ }^{2}$ Social Determinants of Health Research Center, Department of Epidemiology and Biostatistics, Faculty of Health, Birjand University of Medical Sciences, Birjand, Iran \\ ${ }^{3}$ Social Determinants of Health Research Center, Department of Public Health, Faculty of Health, Birjand University of Medical Sciences, Birjand, Iran \\ "Corresponding author: Social Determinants of Health Research Center, Department of Public Health, Faculty of Health, Birjand University of Medical Sciences, Birjand, Iran. \\ Email: noroziensiyeh@yahoo.com
}

Received 2021 February 10; Revised 2021 April 16; Accepted 2021 April 21.

\begin{abstract}
Background: Exclusive breastfeeding (EBF) for the first six months of life is the best nutritional option for the growth and development of infants. EBF has a unique biological and emotional effect on the health of the infant and mother. Despite this, the prevalence of EBF is lower than the standard recommended by the World Health Organization (WHO).

Objectives: The current study aimed to investigate the determinants of exclusive breastfeeding' intention based on the Integrated Behavioral Model (IBM) in pregnant women living in Birjand.

Methods: Following a descriptive-analytical design, 292 pregnant women referred to health centers of Birjand (Iran) in 2020 were recruited. Sampling was performed using the multistage cluster random technique. Data were collected using a researcher-made questionnaire based on the constructs of IBM. Analyses were conducted by SPSS-19 using Pearson correlation and regression analysis at the significance level of $\mathrm{P}<0.05$.

Results: There was a significant positive correlation between EBF intention and the mean value of different constructs of IBM (P $<0.001$ ). According to the results of regression analysis, perceived self-efficacy, experiential attitude, and injunctive norm could predict EBF intentions $\left(\mathrm{R}^{2}=0.58\right)$.

Conclusions: This study demonstrated that a considerable part of the changes relevant to EBF intention could be predicted by the constructs of the integrated behavioral model. Hence, using this model to analyze other health behaviors is a promising option.
\end{abstract}

Keywords: Attitude, Breast Feeding, Intention, Pregnant Women, Self-efficacy

\section{Background}

Early infancy is a crucial period for our growth, which highly depends on nutrition, particularly exclusive breastfeeding (EBF) (1). The World Health Organization (WHO) and the American Academy of Pediatrics recommend that EBF is a natural method of feeding for the first six months (2). According to the definition provided by the WHO, EBF refers to feeding the infant directly by the breast or the breast milk alone or with medications, vitamins, and minerals up to 6 months. In the case of using water, juice, sugar water, tea, decoction, and other foods, the infant is not in the group of EBF anymore (3). Breast milk is the best nutrition for the growth and development of infants, mainly because of its unique biological and emotional effects on the infant and mother health (4). Proteins, vitamins, and carbohydrates in breast milk provide the nutrients required for the infant for at least 6 months.

Also, by improving the immune system function, breast milk not only can prevent various infections (e.g. gastrointestinal, respiratory, and skin infections) but also is associated with enhanced physical and mental growth during infancy (5). Also, for mothers, it is conferred that EBF can cause weight loss and is associated with decreased risk of breast and ovary cancer, post-delivery bleeding and depression, amenorrhea and contraception, osteoporosis in the postmenopausal period, and maternal mental problems (6).

Despite the advantages of EBF, many mothers stop breastfeeding prematurely or use unnecessary fluids or extra nutrition (7). In general, in developing countries, only one out of three infants is fed by breast milk exclusively for the first 6 months of life (8). According to a recent report by WHO, the average coverage of EBF has increased

Copyright ( $)$ 2021, Modern Care Journal. This is an open-access article distributed under the terms of the Creative Commons Attribution-NonCommercial 4.0 International License (http://creativecommons.org/licenses/by-nc/4.0/) which permits copy and redistribute the material just in noncommercial usages, provided the original work is properly cited. 
from $26 \%$ in 2000 - 2005 to $42 \%$ in 2006 - 2011 in 48 countries of the world; however, this value provides lower estimates compared to the standard recommended by the WHO to cover $90 \%$ of countries (9). A study conducted in Iran by Olang et al. (2012) reported that only $56 \%$ of Iranian infants had EBF up to 4 months. They also noted that $28 \%$ of infants had EBF up to 6 months, which is significantly lower than the rate recommended by the WHO (4). Besides, another study reported a prevalence of $44 \%$ for the first 6 months (10). Unfortunately, in developing countries, national compliance to EBF is significantly lower than the recommended rate. Various studies reported different inhibitory factors for EBF. Besides, variables like race, age, job, education level, social-economic factors, insufficiency of breast milk, infant disease, being a singleton, type of childbirth, and tendency of a mother for breastfeeding, can affect the EBF (2). Hawley et al. mentioned that the most underlying beliefs of mothers in EBF include safety of powdered milk, insufficient breast milk, ease of using powdered milk, lack of producing sufficient breast milk, and pain when breastfeeding (11).

One of the most comprehensive models to predict factors with an effective contribution to health behaviors is the integrated behavioral model (IBM), which is presented based on the expansion of the theory of planned behavior. According to this theory, the intention of individuals to take the desired behavior is a function of their attitude toward the behavior (experiential and instrumental attitude), their belief on what their relatives think they should do (descriptive and injunctive norms), and their perception of the hardness or easiness of relevant behavior and personal self-efficacy (12). Unfortunately, despite Ajzen's recommendation to use this model in behavior change, few studies have used this theory so far, which their results indicated the effectiveness of the IBM to predict health behaviors $(12,13)$. Despite various advantages of EBF as well as its crucial role in the growth and development of infants and the health of mothers, many mothers stop breastfeeding prematurely or use unnecessary fluids or extra nutrients. Hence, identification of factors that affect the EBF intention is vital to design effective interventions and to promote this behavior.

\section{Objectives}

The current study aimed to identify the determinants of exclusive breastfeeding intention in pregnant women living in the city of Birjand using IBM.

\section{Methods}

Following a descriptive-analytical design, the current study aimed to analyze the determinants of EBF intention using the IBM framework on 292 eligible pregnant women referred to the health centers in the city of Birjand. The sample size was estimated using the Mean estimation formula and following the study by Rahimi et al. (14). Participants were selected using the using multistage cluster random sampling technique. To this end, the city of Birjand was divided into four similar regions, and a health center was selected in each region using the simple random sampling technique from the list of health centers located in each region. Afterward, in each center, the list of potentially eligible pregnant women was retrieved from the SIB website. Due to the sample size and population size, the samples of each center were selected using systematic random sampling. The inclusion criteria were informed consent to participate in the study, having at least primary literacy, not having a job history in works related to the health sector, not being a healthcare worker, and being healthy (both physical and mental health). Data were collected using a researcher-made questionnaire with two sections on demographic information (age of mother, education level, spouse job, etc.) and items related to the IBM. The "awareness" dimension contained 7 items, and each correct answer choice had one point, and each incorrect answer had zero point; the "experiential attitude" contained 5 items; instrumental attitude included 8 items; descriptive norm included 4 items; injunctive norm included 8 items; perceived behavioral control included 6 items; behavioral intention contained 3 items; and perceived self-efficacy included 8 items. The responses were scored based on a 5-point Likert scale, ranging from 1 ("strongly disagree") to 5 ("strongly agree"). A deductive approach was followed in order to develop items, which requires a theoretical definition of the construct under examination. In this study, Ajzen's theoretical framework was used as the theoretical foundation to define the structure of items. The item development process began with a comprehensive review of published research on IBM and its measurement. Also, two focus groups were conducted to gain a comprehensive understanding of the IBM constructs in the context of Iranian pregnant women and to propose items related to the IBM constructs. A series of focus groups were held with experts on health education and health promotion. The validity of the questionnaire was evaluated by 10 experts in the field of Health Education and Health Promotion. For this reason, generated items were subjected to a content validity assessment [content validity ratio (CVR) and content validity index (CVI)]. In order to evaluate the CVR, participating experts were asked to rate each item of the questionnaire on a 3 point Likert scale (i.e. necessary, helpful but not necessary, and not necessary). The obtained ratios for each item were compared with the numbers provided by Lawsche (15). If the calculated value was greater than the number given in the Lawsche table (for this study: CVR > 0.62), the item was 
considered necessary. Lynn's descriptive method (itemCVI) was employed to evaluate the CVI (16). Based on the pattern of Lynn, the experts were asked to rate each item concerning its simplicity [ranging from 1 ("not simple") to 4 ("strongly simple")], relevance [ranging from 1 ("not relevant") to 4 ("highly relevant")], and clarity [1 ("not clear") to 4 ("strongly clear")] on a four-point Likert scale. Based on the Lynn method, if the number of experts is 6 or more, the index should not be less than 0.78 (16). A pilot study was conducted on 20 eligible women to evaluate the reliability of the questionnaire. Also, the internal consistency of items was evaluated using Cronbach's alpha. A coefficient of 0.85 was obtained for the questionnaire. Concerning its dimension, a coefficient of 0.91 was obtained for the perceived self-efficacy, 0.69 for experiential attitude, 0.7 for the instrumental attitude, 0.87 for descriptive norm, 0.98 injunctive norms, and 0.91 for the perceived behavioral control. The questionnaire was filled out in a self-administered manner. However, those unable to fill the questionnaire were interviewed verbally, and their responses were noted.

Initially, the objectives of the study were described for eligible participants. Then, if agreeing, written informed consent was obtained. Also, they were ensured about the confidentiality of their information. In addition, they were informed that they can withdraw from the study at any time. The study is approved by the Ethics Committee of the Birjand University of Medical Sciences (Ir.BUMS.REC.2020. 493). Data were analyzed using SPSS version 19 by descriptive statistics, Pearson correlation test, and regression analysis. Statistical significance was considered when Pvalue $<0.05$

\section{Results}

In this study, 292 eligible pregnant women were investigated, with a mean age of $25.87 \pm 5.91$ years. The youngest and oldest participants were 16 and 45 years old, respectively. Most of the participants (43.5\%) had an academic educational degree. Also, 84.2\% $(\mathrm{n}=248)$ were housewives. In terms of income level, 204 (96.9\%) had an average income level (Table 1).

According to the findings, there was a significant correlation between the value of EBF intention and the mean value of IBM's constructs (Table 2).

According to the results of the regression analysis, the variables of perceived self-efficacy, experiential attitude, and injunctive norm, respectively, had the highest effect on $\mathrm{EBF}$ intention. Also, 58\% of EBF intention variance was explained by the IBM structures (Table 3 ).

\section{Discussion}

Exclusive breastfeeding plays a key role in the health, growth, and development of children and the health of

\begin{tabular}{|c|c|}
\hline Variables & No. $(\%)$ \\
\hline \multicolumn{2}{|l|}{ Mother's education level } \\
\hline Elementary school & $9(3.1)$ \\
\hline Middle school & $33(11.3)$ \\
\hline High school & $24(8.2)$ \\
\hline Diploma & $99(33.9)$ \\
\hline Higher education & $127(43.5)$ \\
\hline \multicolumn{2}{|l|}{ Spouse's education level } \\
\hline Elementary school & $10(3.4)$ \\
\hline Middle school & $22(7.5)$ \\
\hline High school & $30(10.3)$ \\
\hline Diploma & $110(37.7)$ \\
\hline Higher education & $120(41.1)$ \\
\hline \multicolumn{2}{|l|}{ Mother's job } \\
\hline Housewife & $248(84.9)$ \\
\hline Employee & $17(5.8)$ \\
\hline Freelance & $27(9.3)$ \\
\hline \multicolumn{2}{|l|}{ Spouse job } \\
\hline Manual worker & $58(19.9)$ \\
\hline Employee & $99(33.9)$ \\
\hline Freelance & $118(40.4)$ \\
\hline Unemployed & $8(2.7)$ \\
\hline Other & $9(3.1)$ \\
\hline \multicolumn{2}{|l|}{ Income } \\
\hline Good & $32(11)$ \\
\hline Medium & $204(69.9)$ \\
\hline Weak & $56(19.1)$ \\
\hline Total & $292(100)$ \\
\hline
\end{tabular}

mothers $(17,18)$. According to the American Academy of Pediatrics, breast milk is the golden standard of nutrition for infants $(19,20)$. Although almost the majority of women have the ability of breastfeeding, many infants are deprived of breastfeeding. This study aimed to analyze factors that contribute to EBF intention in pregnant women living in the city of Birjand based on the IBM constructs.

According to the findings, the perceived self-efficacy of pregnant mothers had the highest contribution to EBF intention. Hence, it can be argued that programs intended to improve this variable are of crucial importance for the promotion of EBF intention. Perceived self-efficacy refers to the state that a person feels personal competence to take a measure or is relied on the ability of self to do something (21). In this study, perceived self-efficacy was defined as the 


\begin{tabular}{|c|c|c|c|c|c|c|c|c|}
\hline \multirow{2}{*}{ Variables } & \multicolumn{7}{|c|}{$\mathbf{r}$} & \multirow{2}{*}{ Mean \pm SD } \\
\hline & Awareness & $\begin{array}{c}\text { Experiential } \\
\text { Attitude }\end{array}$ & $\begin{array}{c}\text { Instrumental } \\
\text { Attitude }\end{array}$ & $\begin{array}{l}\text { Descriptive } \\
\text { Norm }\end{array}$ & $\begin{array}{l}\text { Injunctive } \\
\text { Norm }\end{array}$ & $\begin{array}{c}\text { Behavioral } \\
\text { Control }\end{array}$ & Self-efficacy & \\
\hline Awareness & - & - & - & - & - & - & - & $2.4 \pm 1.64$ \\
\hline $\begin{array}{l}\text { Experiential } \\
\text { attitude }\end{array}$ & $0.44^{\mathrm{a}}$ & - & - & - & - & - & - & $8.4 \pm 2.91$ \\
\hline $\begin{array}{l}\text { Instrumental } \\
\text { attitude }\end{array}$ & $0.42^{\mathrm{a}}$ & $0.61^{\mathrm{a}}$ & - & - & - & - & - & $18.6 \pm 4.79$ \\
\hline $\begin{array}{l}\text { Descriptive } \\
\text { norm }\end{array}$ & $0.29^{\mathrm{a}}$ & $0.51^{\mathrm{a}}$ & $0.37^{\mathrm{a}}$ & - & - & - & - & $10.8 \pm 4.36$ \\
\hline $\begin{array}{l}\text { Injunctive } \\
\text { norm }\end{array}$ & $0.21^{\mathrm{a}}$ & $0.40^{\mathrm{a}}$ & $0.37^{\mathrm{a}}$ & $0.64^{\mathrm{a}}$ & - & - & - & $7.12 \pm 2.92$ \\
\hline $\begin{array}{l}\text { Behavioral } \\
\text { control }\end{array}$ & $0.28^{\mathrm{a}}$ & $0.43^{\mathrm{a}}$ & $0.56^{\mathrm{a}}$ & $0.26^{\mathrm{a}}$ & $0.30^{\mathrm{a}}$ & - & - & $17.02 \pm 4.70$ \\
\hline Self-efficacy & $0.32^{\mathrm{a}}$ & $0.49^{\mathrm{a}}$ & $0.42^{\mathrm{a}}$ & $0.53^{\mathrm{a}}$ & $0.44^{\mathrm{a}}$ & $0.35^{\mathrm{a}}$ & - & $13.5 \pm 4.82$ \\
\hline Intention & $0.31^{\mathrm{a}}$ & $0.49^{\mathrm{a}}$ & $0.34^{\mathrm{a}}$ & $0.53^{\mathrm{a}}$ & $0.46^{\mathrm{a}}$ & $0.29^{\mathrm{a}}$ & $0.73^{\mathrm{a}}$ & $4.71 \pm 1.97$ \\
\hline
\end{tabular}

${ }^{\mathrm{a}}$ P-value $<0.001$.

Table 3. Summary of the Results of Multivariate Regression Test (Stepwise Method) to Investigate the Factors Affecting the Intention of Exclusive Breastfeeding in Pregnan Women $^{\mathrm{a}}$

\begin{tabular}{|c|c|c|c|}
\hline Variables & Beta & $t$ & P-Value \\
\hline Awareness & 0.04 & 0.98 & 0.32 \\
\hline Experiential attitude & 0.15 & 2.83 & 0.005 \\
\hline Instrumental attitude & 0.09 & 1.72 & 0.086 \\
\hline Descriptive norm & 0.1 & 1.93 & 0.05 \\
\hline Injunctive norm & 0.10 & 2.02 & 0.044 \\
\hline Perceived behavioral control & 0.001 & 0.024 & 0.98 \\
\hline Self-efficacy & 0.57 & 11.87 & 0.001 \\
\hline
\end{tabular}

${ }^{\mathrm{a}}$ Regression indices: $\mathrm{P}$-value $=0.0001 ; \mathrm{R}^{2}=0.58$, and $\mathrm{F}=57.68$.

perceived ability of pregnant mothers to take successful breastfeeding and to overcome the barriers of breastfeeding such as nocturnal insomnia, breast fissure and diet, milking difficulty, mother's fatigue, being busy, and time shortage. The findings of the present study are consistent with the study by De Jager et al. in Australia, entitled "Psychosocial Correlates of Exclusive Breastfeeding". Also, the findings showed that those women with high selfefficacy in the first six months of pregnancy experienced fewer breastfeeding problems compared to their counterparts. The results showed that self-efficacy has a strong and significant contribution to the promotion of EBF (22). A study conducted by Wilhelm et al. showed that high perceived self-efficacy of mothers for breastfeeding in the second week after childbirth was significantly correlated to an increased probability of EBF to the end of six months (23).

In this study, the experiential attitude was the second underlying predictor of EBF intention. Experiential attitude is the emotional response of individuals to the idea of following a behavior and intends to measure the emotions of individuals toward the recommended behavior. Some studies reported a correlation between attitude and EBF intention $(14,22)$. For instance, Rahimi et al. showed that making an emotional relationship with an infant during breastfeeding is an underlying positive attitude for pregnant mothers, which can have a significant effect on EBF intention and continuation of breastfeeding (6). According to the study by Waling et al., 76\% of mothers believed that early breastfeeding can increase the emotional connection between mother and infant (24). According to the literature, EBF can cause an emotional relationship between infant and mother because of skin contact and secretion of oxytocin in both of them. In addition, it causes emotional stability of the baby (25).

Besides, Wojcicki et al. mentioned positive attitudes of mothers in California in the field of exclusive breastfeeding: cost-effectiveness of breast milk compared to powdered milk, providing health for the baby, and preventing 
obesity of the baby (26). In the study conducted by Lawton et al, emotional attitude is mentioned as the best predictor of EBF for white mothers (27). In the present study, factors like beliefs of women on the cost-effectiveness of breast milk and easy access as well as expensiveness of powdered milk and its side effects have been considered as factors that affect experiential attitude.

The findings also indicated that the injunctive norm could affect the EBF intention. Injunctive norm refers to injunctive social pressures. It means the emphasis of families and relatives on doing or not doing something, which is consistent with the findings of Lawton and colleagues. According to the findings of Lawton, the best predictor of EBF intention for American and African mothers was the subjective norm (27). Bai et al. also showed that perceived social support on behalf of the family can be the most underlying normative belief that affects the EBF duration (28).

It is necessary to mention some limitations of our study, including using a researcher-made questionnaire and following a cross-sectional design. In addition, the sample size was not large enough. Hence, caution should be taken when generalizing the results of the present study.

\subsection{Conclusion}

This study demonstrated that the constructs of perceived self-efficacy, experiential attitude, and injunctive norm could predict the EBF intention. Hence, as according to the best knowledge of the authors, no previous study has applied an IBM to promote the EBF intention, it is recommended to conduct further in-depth studies on using IBM for educational purposes.

\section{Acknowledgments}

The current study is approved by the Research Council of the Birjand University of Medical Sciences (project code: 5375 ). The authors would like to appreciate the vicechancellor for the Research and Technology of the university, participants, and all people who helped us in this research.

\section{Footnotes}

Authors' Contribution: E. N., Z. G., and Gh. Sh. designed the study. Gh. Sh. analyzed and interpreted the data. Z. G. participated in data collection and data management. E. N. and Z. G. were major contributors to the writing of the manuscript. All authors read and approved the final manuscript.

Conflict of Interests: The authors declare no conflict of interest.
Ethical Approval: All procedures were approved by the Ethics Committee of the Birjand University of Medical Sciences (Ir.BUMS.REC.2020.493). After explaining the objectives of the study to all potential participants, written informed consent was obtained. Also, they were ensured about the confidentiality of their information. In addition, they were informed that they can withdraw from the study at any time.

Funding/Support: This study was supported by the Birjand University of Medical Sciences (project code: 5375).

Informed Consent: Written informed consent was obtained from all the participants.

\section{References}

1. Ghanbarnejad A, Abedini S, Taqipoor L. [Exclusive breastfeeding and its related factors among infants in Bandar Abbas city, Iran]. J Babol Univ Medical Sci. 2014;16(1):85-91. Persian.

2. Krol KM, Grossmann T. Psychological effects of breastfeeding on children and mothers. Bundesgesundheitsblatt Gesundheitsforschung Gesundheitsschutz. 2018;61(8):977-85. doi: 10.1007/s00103-018-2769-0. [PubMed: 29934681]. [PubMed Central: PMC6096620].

3. Figueiredo B, Canario C, Field T. Breastfeeding is negatively affected by prenatal depression and reduces postpartum depression. Psychol Med.2014;44(5):927-36. doi:10.1017/S0033291713001530.[PubMed: 23822932].

4. Olang B, Heidarzadeh A, Strandvik B, Yngve A. Reasons given by mothers for discontinuing breastfeeding in Iran. Int Breastfeed $\mathrm{J}$. 2012;7(1):7. doi: 10.1186/1746-4358-7-7. [PubMed: 22559297]. [PubMed Central: РMC3407704].

5. McDonald SD, Pullenayegum E, Chapman B, Vera C, Giglia L, Fusch $C$, et al. Prevalence and predictors of exclusive breastfeeding at hospital discharge. Obstet Gynecol. 2012;119(6):1171-9. doi: 10.1097/AOG.0b013e318256194b. [PubMed: 22617582].

6. Rahimi T, Dehdari T, Shojaei S, Hashemi BS, Akbari Z, Daryafti H. [Beliefs of pregnant women in Qom city about exclusive breastfeeding until 6 months of age, Iran]. Qom Univ Med Sci J. 2016;10(2):60-9. Persian.

7. Ziaie T, Ghanbari A, Hassanzadeh Rad A, Yazdani MA. [Investigating risk factors of failure in exclusive breastfeeding in less than one-yearold children referred to health centers in Rasht city]. The Iranian Journal of Obstetrics, Gynecology and Infertility. 2012;15(18):32-9. Persian.

8. Cai X, Wardlaw T, Brown DW. Global trends in exclusive breastfeeding. Int Breastfeed J. 2012;7(1):12. doi: 10.1186/1746-4358-7-12. [PubMed: 23020813]. [PubMed Central: PMC3512504].

9. Haroon S, Das JK, Salam RA, Imdad A, Bhutta ZA. Breastfeeding promotion interventions and breastfeeding practices: A systematic review. BMC Public Health. 2013;13 Suppl 3. S20. doi: 10.1186/1471-2458-13-S3-S20. [PubMed: 24564836]. [PubMed Central: PMC3847366].

10. Hatami G, Motamed N. The timing and predictors of the early discontinuation of breastfeeding in southwest Iran. Iran $J$ Pediatr. 2012;22(3):430-1. [PubMed: 23399929]. [PubMed Central: PMC3564106].

11. Hawley NL, Rosen RK, Strait EA, Raffucci G, Holmdahl I, Freeman JR, et al. Mothers' attitudes and beliefs about infant feeding highlight barriers to exclusive breastfeeding in American Samoa. Women Birth. 2015;28(3):e80-6. doi: 10.1016/j.wombi.2015.04.002. [PubMed: 25935567].

12. Glanz K, Rimer BK, Viswanath K. Health behavior and health education: theory, research, and practice. 4 th ed. New Jersey, USA: John Wiley \& Sons; 2008. 
13. Gandomi M, Sharifzadeh G, Akbari N, Gandomi N, Delpasand M, Nowruzi E. [The Application of Integrated Behavioral Model in determining preventive behaviors dental caries in mothers with 4-6 yearold children in Birjand].J Birjand Univ Med Sci. 2019;26(2):165-75. Persian. doi: 10.32592/JBirjandUnivMedSci.2019.26.2.108.

14. Rahimi T, Dehdari T, Faryabi R, Ghazvinian L. [The applicability of the theory of planned-behavior in predicting the intention to exclusive breast-feeding among pregnant women in Qom in 2014]. J Rafsanjan Univ Med Sci. 2015;14(4):299-310. Persian.

15. Lawshe $\mathrm{CH}$. A quantitative approach to content validity. Pers Psychol. 1975;28(4):563-75. doi: 10.1111/j.1744-6570.1975.tb01393.x.

16. Lynn MR. Determination and quantification of content validity. Nurs Res. 1986;35(6):382-5. [PubMed: 3640358].

17. Victora CG, Bahl R, Barros AJ, Franca GV, Horton S, Krasevec J, et al. Breastfeeding in the 21st century: Epidemiology, mechanisms, and lifelong effect. Lancet. 2016;387(10017):475-90. doi: 10.1016/S01406736(15)01024-7. [PubMed: 26869575].

18. Marshall JL, Godfrey M, Renfrew MJ. Being a 'good mother': Managing breastfeeding and merging identities. Soc Sci Med. 2007;65(10):214759. doi: 10.1016/j.socscimed.2007.06.015. [PubMed:17681409].

19. Pediatrics AA, Gynecologists ACO, Schanler R, Krebs N. Breastfeeding handbook for physicians. 2nd ed. Illinois, USA: American Academy of Pediatrics; 2013.

20. World Health Organization; Department of Maternal Newborn Child Adolescent Health. WHO recommendations on postnatal care of the mother and newborn. Geneva, Switzerland: World Health Organization; 2013.

21. Araban M, Tavafian SS, Zarandi SM, Hidarnia AR, Burri A, Montazeri A. A behavioral strategy to minimize air pollution exposure in pregnant women: A randomized controlled trial. Environ Health Prev Med. 2017;22(1):26. doi: 10.1186/s12199-017-0633-8. [PubMed: 29165105].
[PubMed Central: PMC5664830].

22. de Jager E, Broadbent J, Fuller-Tyszkiewicz M, Skouteris $\mathrm{H}$. The role of psychosocial factors in exclusive breastfeeding to six months postpartum. Midwifery. 2014;30(6):657-66. doi: 10.1016/j.midw.2013.07.008. [PubMed: 23932036].

23. Wilhelm SL, Rodehorst TK, Stepans MB, Hertzog M, Berens C. Influence of intention and self-efficacy levels on duration of breastfeeding for midwest rural mothers. Appl Nurs Res. 2008;21(3):123-30. doi: 10.1016/j.apnr.2006.10.005. [PubMed: 18684405].

24. Walingo MK, Mutuli LA. Influence of maternal beliefs, attitude, perceived behavior on breast-feeding among post partum mothers in Western Kenya. Pak J Nutr. 2014;13(5):250-4. doi: 10.3923/pjn.2014.250.254.

25. Oddy WH, Kendall GE, Li J, Jacoby P, Robinson M, de Klerk NH, et al. The long-term effects of breastfeeding on child and adolescent mental health: A pregnancy cohort study followed for 14 years. $J P e$ diatr. 2010;156(4):568-74. doi: 10.1016/j.jpeds.2009.10.020. [PubMed: 20004910].

26. Wojcicki JM, Gugig R, Tran C, Kathiravan S, Holbrook K, Heyman MB Early exclusive breastfeeding and maternal attitudes towards infant feeding in a population of new mothers in San Francisco, California. Breastfeed Med. 2010;5(1):9-15. doi: 10.1089/bfm.2009.0003. [PubMed: 19772374]. [PubMed Central: PMC2936253].

27. Lawton R, Ashley L, Dawson S, Waiblinger D, Conner M. Employing an extended theory of planned behaviour to predict breastfeeding intention, initiation, and maintenance in White British and SouthAsian mothers living in Bradford. Br J Health Psychol. 2012;17(4):854-71. doi: 10.1111/j.2044-8287.2012.02083.x. [PubMed: 22950369].

28. Bai Y, Middlestadt SE, Peng CY, Fly AD. Predictors of continuation of exclusive breastfeeding for the first six months of life. J Hum Lact. 2010;26(1):26-34. doi: 10.1177/0890334409350168. [PubMed: 19910521]. 